\title{
Comparing the Leverage Effect of Different Frequencies of Stock Returns in an Emerging Market: A Case Study of Pakistan
}

\author{
${ }^{-*}$ Amir Rafique 1 Kashif-Ur-Rehman² \\ 1SZABIST Islamabad, Pakistan \\ 2Iqra University Islamabad Campus, Pakistan \\ *raja_kiyani@yahoo.com
}

\begin{abstract}
This study compares the volatility behavior and variance structure of high (daily) and low (weekly, monthly) frequencies of data. The study used seventeen years data from 1991 to 2008 of KSE-100 index. By employing Exponential GARCH (EGARCH) model (asymmetric type GARCH model), the study finds evidence that there are significant asymmetric shocks (leverage effect) to volatility in the three series but the intensity of the shocks are not equal for all the series. The results show that the variance structure of high frequencies data is dissimilar from the low frequencies data.
\end{abstract}

Keywords: Asymmetric GARCH models, KSE-100 index, leverage effect.

\section{Introduction}

The publication of paper on ARCH by Engle (1982) was the starting point of a new debate on volatility for researchers, practitioners and policy makers. The interest on stock returns volatility is due to reason that volatility is a risk measure and different market players use this measure for different purposes. The positive and negative shocks of equal scale have a different impact on returns volatility, which is attributed as "Leverage effect" (Black, 1976). Dawood (2007) investigated this phenomenon for Karachi stock exchange (KSE) and found that in 1990's the market was more volatile on daily (short-term) and monthly (medium term) basis. Rizwan and Khan (2007) also found presence of leverage effect for the Pakistani capital market using country and global factors. Ali \& Akbar (2007) tested the equality in returns on daily, weekly and monthly basis and found insignificant results.

Information is the driving force for the heterogeneity of volatility of returns. Schwert (1990) investigated the behavior of daily stock returns before, during and after the October 1987 crash. Results stated that volatility was much higher during and after the crash, and it returned to the adequate level quickly. High-frequency data series is considered to the most volatile series as compared to low frequencies of data. As Chang (2006) investigated the mean reversion behavior of different series of data and concluded that the behavior was different for high-frequency data and low-frequency data. Caiado (2004) investigated Portuguese Stock Index (PSI-20) and found support for asymmetric shocks in the daily returns, but not in the weekly returns. This establishes the need for this study to compare the variance structure of different frequencies of data. This study fills the gap by addressing the issues of significant Leverage effect in Karachi stock market for the different frequencies of data. The study has the objectives "to compare the variance structure and leverage effects of high (daily) and low (weekly, monthly) frequencies of data".

Pakistan's Capital Market: Karachi Stock Exchange (KSE) is Pakistan's first and biggest stock market, established in September 1947, where above 650 companies were listed in KSE at the end of the year 2007 having above US $\$ 95$ Billion of market capitalization and US\$15 Billion as listed capital. KSE-100 index is the market capitalization weighted index of 100 stocks of top market capitalized companies and is normally used as a proxy of overall market. The market was $1^{\text {st }}$ and $3^{\text {rd }}$ in 2003 and 2006 respectively when we see the turnover ratio of the market. After the liberalization of economy in 1990's, modest growth is observed in the stock market over the years. During the years 1995-2004, the growth assumed a smooth upward curve. The market faced a severe depression in late 1990's and early 2000's; the mid years of 2000's witnessed a 
significant growth. This performance of KSE-100 index continued for a long period and in March 2005, the market broke the barrier of 10,000.

\section{Literature Review}

Stock returns volatility represents the variability in stock prices (Karolyi, 2001). Volatility is time dependent and time varying and it follows the heteroskedastic process. Strong evidence of heteroskedasticity was found in Bombay Stock Exchange from the period 1979 to 1995 (Thomas, 1995). GARCH models were used for approximating the conditional variance of the three data series. Rehim (2008) found that the GARCH effects are prominent in the high frequency (daily and weekly) data and less for the low-frequency (monthly) data. Kovacic (2008) investigated the Macedonian stock index returns behavior, found autocorrelation of returns, and leverage effect in the market.

The GARCH type models are the best models in modeling and capturing these time series properties of stock prices. Mcmillan, et.al (2000) also employed a variety of models on UK FTA all share index and FTSE-100 index and concluded that most consistence performance were of GARCH models. Chen \& Lian (2005) also found the same results, where they examined the Asian equity markets and found that for the crisis (shocks) TARCH and EGARCH models are the best models, which adequately capture the time varying volatility. Leverage effect, an important stylized fact, is more linked with the developing financial markets than the developed markets. The leverage effect is expected to appear in the emerging markets (Prymachenko, 2003). The leverage effect shows heterogeneous affects of normal and unusual news on stock returns. Maheuy \& McCurdyz (2003) investigated individual companies and three indices, and concluded that the conditional variance is a combination of high and smooth innovations. They found asymmetric responses on market for good and bad news. Floros (2008) also found the same results for the Israel's stock market (TASE-100 Index).

Leverage effect is also affected by the frequency of data. As Caiado (2004) found Leverage effect only in the daily data of PSI-20 index. Unusual events put much stress on financial markets. Aktas \& Oncu (2006) examined the behavior of Turkish stock market on the event of rejection of the bill, which allows deployment of US troops in Turkey, which was presented in the parliament in March 2003. The first trading day after the refusal of the bill, stock market went down and volatility was very high. Magnus \& Fosu (2006) investigated the Ghana stock market and concluded that EGARCH model is also suitable for the African stock markets. Prymachenko (2003) applied TGARCH model in the Ukrainian market and found the presence of leverage effect and acknowledged the measurement by the GARCH type models. Pasha, et.al (2007) employed GARCH type models to characterize returns volatility in Pakistan and found that the EGARCH and GJR Threshold ARCH models had superior measurement ability.

Litvinova (2003) measured the leverage effect accurately with higher frequency data only. The study also concluded that the inability to measure this property with low frequency data was due to the loss of information in low-frequency data. Peiró (2001) examined twenty-four individual stocks at different frequencies: daily, weekly and monthly, and concluded that some asymmetries are observed in daily returns, whereas these asymmetries completely disappear at lower frequencies (weekly or monthly returns). Dawood (2007) investigated Karachi stock exchange and found that in 1990's market has become more volatile both on short term (daily) and medium term (monthly) basis. He found that the stock market reacts too actively to economic shocks on a daily basis and less active on monthly returns. Rizwan and Khan (2007) found leverage effect for the Pakistani capital market by using different factors (country and global).

\section{Data and Procedure}

Data and Sample Period: The study used the daily, weekly and monthly KSE-100 index log returns, rt $=\log$ (It/It-1). All the data are obtained from finance.yahoo.com. For the returns the study considers daily, weekly and monthly closing price data from November 1991 to January 2009 for a total of 4086, 873 and 201 observations, respectively. The period was selected because the liberalization period started after 1991 and before the liberalization period, the market was totally dead so the liberalization process activated the market. 
Procedure: The current study employs following tests:

1. Augmented Dickey Fuller (ADF) test

2. EGARCH

The ADF test is used to check the hypothesis of null of unit root in the time series data and the EGARCH model is employed to measure the presence of leverage effect in the returns series.

\section{Results and Discussion}

Table 1: Summary Statistics of the Series

\begin{tabular}{lrrr}
\hline & Daily & Weekly & Monthly \\
\hline Mean & .00044 & .002 & .0082 \\
Kurtosis & 8.097 & 5.70 & 5.74 \\
Standard Deviation & .017 & .04 & .10032 \\
Jarque-Bera & 4477.30 & 321.50 & 84.14 \\
Observations & 4086 & 873 & 201 \\
\hline
\end{tabular}

The results show that all the data series show different statistical characteristics from each other confirming the results of Caiado (2004) and Ali \& Akbar (2007). Non-normal characteristics found in the results also confirm the results of Andersen et. al (2001), Magnus \& Fosu (2006), Khedhiri \& Muhammad (2008) and Eisler (2007). Turan et. al (2006) and Zhu (2007) also concluded that volatility follows the time varying dynamic process/ characteristics. The developing markets are mostly affected by these characteristics as confirmed by Hassan et. al (2000) and Li (2007). Thomas (1995) also found the presence of heteroskedasticity in daily, weekly and monthly returns in Bombay Stock Exchange. The results show that the daily data has more volatility as compared to other two series. These results also confirm the findings of Dawood (2007) for the Karachi stock exchange.

Below are the results for the presence of the leverage effects in the three data series.

\section{Daily Stock Returns}

Table 2: ADF test

ADF Test Statistic -25.254

Table 3: EGARCH

\begin{tabular}{lllll}
\hline & Coefficient & Std. Error & z-Statistic & Prob. \\
\hline & \multicolumn{1}{l}{ Variance Equation } & & \\
\hline |RES|/SQR[GARCH](1) & 0.373 & 0.0162 & 23.10 & 0.00 \\
RES/SQR[GARCH](1) & 0.024 & 0.01 & 2.48 & 0.013 \\
EGARCH(1) & 0.93 & 0.01 & 174.72 & 0.00 \\
\hline
\end{tabular}

\section{Weekly Stock Returns}

Table 4: ADF test 
Table 5: EGARCH $(1,1)$

\begin{tabular}{|c|c|c|c|c|}
\hline & Coefficient & Std. Error & z-Statistic & Prob. \\
\hline & \multicolumn{4}{|c|}{ Variance Equation } \\
\hline |RES|/SQR[GARCH](1) & 0.37 & 0.04632 & 7.935 & 0.00 \\
\hline RES/SQR[GARCH](1) & $-0.007^{*}$ & 0.026 & -0.303 & 0.76 \\
\hline EGARCH(1) & 0.835 & 0.035 & 24.03 & 0.00 \\
\hline
\end{tabular}

\section{Monthly Stock Returns}

Table 6: ADF test

ADF Test Statistic

$-5.84$

Table 7: EGARCH $(1,1)$

\begin{tabular}{lllll}
\hline & Coefficient & Std. Error & z-Statistic & Prob. \\
\cline { 2 - 5 } & Variance Equation & & & \\
\hline |RES|/SQR[GARCH](1) & 0.51 & 0.14 & 3.67 & 0.00 \\
RES/SQR[GARCH](1) & -0.178 & 0.078 & -2.2642 & 0.024 \\
EGARCH(1) & -0.2804 & 0.254 & -1.1045 & 0.27 \\
\hline
\end{tabular}

The leverage effect, like developing markets, is also found in Pakistan so confirming the findings of Prymachenko (2003). The results show that the magnitude of the leverage effect is different for the three series, so confirming the results of Caiado (2004), who found leverage effect for the daily returns only. In short the study concludes that volatility-return relation can be best-measured using higher frequency data due to more information in the high frequencies of data. Peiro (2001) also found the same results and concluded that some asymmetries are observed in daily returns only. Asymmetric GARCH type models resulted to be the good models for estimating leverage effect in the developing markets. Magnus \& Fosu (2006) modeled volatility for the Ghana stock exchange and concluded that univariate asymmetric class of GARCH models is appropriate for the analysis of the developing markets. The insignificant values of leverage effect, for the high-frequency data (daily data) as compared to low-frequency data (monthly data), contradict the studies of Caiado (2004), Zakoian (1994), Nelson (1991) and others. The results show that the volatility measurement is sensitive to the frequency of the data set used confirming the results of $\mathrm{Ng}$ and McAleer (2004). The results state that the Karachi stock market is more volatile for the short-term basis as compared to the long-term basis confirming the results of Dawood (2007).

\section{Conclusion and Summary}

The objective of the study is to compare the volatility structure of the daily, weekly and monthly data series of KSE-100 index and to investigate leverage effect in the market by applying the asymmetric GARCH type model. There is evidence that the three data series (daily, weekly and monthly) has different statistical properties, confirming the results of Andersen et. al (2001), Magnus et. al (2006), Khedhiri and Muhhamad (2008) and Eisler (2007). The daily data shows more volatile characteristics than other two series confirming the results of Dawood (2007) for the Karachi stock exchange. The study finds that the Pakistani stock market becomes much nervous when negative shocks take place confirming the findings of Engle et al (1993) and Nelson (1991) and others. The leverage effect terms show that the leverage effect for the daily data is different from the weekly and monthly data confirming the results of Caiado (2004).

The results of the study are summarized as follows:

- The daily data shows more volatile characteristics than other two series and the properties of the three data series are different from one another.

- The study finds presence of leverage effect in the market. 
- The leverage effect is more in the case of the monthly data than the weekly data. The intensity of leverage effect in the series is different from one another.

- The inability of previous studies to measure volatility accurately was due to the loss of information in low-frequency data and different features of low and high frequency data.

The findings have many implications like:

- Modeling the returns volatility gives different results for different frequencies.

- High-frequency data are more volatile than the low-frequency data.

For future research the shocks and breaks can be incorporated in the volatility models by using other techniques like iterated cumulative sum of squares (ICSS) and Wavelet method. Individual firms can be investigated with the same methodology.

\section{References}

Aktas, H. \& Oncu, S. (2006). The Stock Market Reaction to Extreme Events: The Evidence from Turkey. International Research Journal of Finance and Economics, 6, 1450-2887.

Ali, S. \& Akbar, M. (2007). Calendar Effects in Pakistani Stock Market, Unpublished Research Paper.

Andersen, T. G., Bollerslev, T., Deibold, F. X. \& Ebens, H. (2001). The Distribution of Stock Return Volatility, Journal of Financial Economics, 61, 43-76.

Black, F. (1976). Studies of Stock Price Volatility Changes, Proceedings of the 1976 Meetings of the American Statistical Association, Business and Economic Statistics Section, 177-181.

Caiado, J. (2004). Modelling and forecasting the volatility of the portuguese stock index PSI-20, Munich Personal RePEc Archive (MPRA) Paper No. 2304, posted 07.

Chang, C. H. (2006). Mean Reversion Behavior of Short-term Interest Rate Across Different Frequencies, Unpublished Research.

Chen, W. Y. \& Lian, K. K. (2005). A Comparison of Forecasting Models for Asean equity Markets. Sunway Academic Journal, 2, 1-12.

Dawood, M. (2007). Macro Economic Uncertainty of 1990s and Volatility at Karachi Stock Exchange, Munich Personal RePEc Archive (MPRA) Paper, 3219.

Dickey, D. A. \& Fuller, W. A. (1979). Distribution of the estimators for autoregressive time series with a unit root, Journal of the American Statistical Association, 74, 427-431.

Eisler, B. Z. (2007). Fluctuation Phenomena on the Stock Market, Unpublished Ph.D. Thesis.

Engle, R. F. (1982). Autoregressive Conditional Heteroscedasticity with Estimates of the Variance of United Kingdom Inflation, Econometrica, 50(4), 987-1007.

Engle, R. F. \& Ng, V. K. (1993). Measuring and Testing the Impact of News on Volatility. Journal of Finance, 48, 1749-1778.

Floros, C. (2008). Modelling Volatility using GARCH Models: Evidence from Egypt and Israel. Middle Eastern Finance and Economics, 2, 1450-2889.

Hassan, M. K., Islam, A. M. \& Basher, D. (2000). Market Efficiency, Time-Varying Volatility and Equity Returns in Bangladesh Stock Market, Working Paper, Department of Finance and Economics, University of New Orleans.

Karolyi, G. A. (2001). Why Stock Return Volatility Really Matters. Institutional Investor Series, prepared for inaugural issue of strategic investor relations.

Khedhiri, S. \& Muhammad, N. (2008). Empirical Analysis of the UAE Stock Market Volatility. International Research Journal of Finance and Economics, 15, 1450-2887.

Kovacic, Z. (2008). Forecasting volatility: Evidence from the Macedonian stock exchange. International Research Journal of Finance and Economics, 18, 1450-2887.

Li, J. (2007). Three Essays on Modeling Stock Returns: Empirical Analysis of the Residual Distribution, RiskReturn Relation, and Stock-Bond Dynamic Correlation, Unpublished Ph. D Thesis.

Litvinova, J. (2003). Volatility Asymmetry in High Frequency Data, Duke Financial Econometrics group, September 16. 
Maheuy, M. J. \& McCurdyz, T. H. (2003). News Arrival, Jump Dynamics and Volatility Components for Individual Stock Returns, Unpublished Research Paper.

Magnus, F. J. \& Fosu, A. E. (2006). Modelling and Forecasting Volatility of Returns on the Ghana Stock Exchange Using Garch Models. American Journal of Applied Sciences, 3(10), 2042-2048, 2006 ISSN 1546-9239.

McMillan, D., Speight, A. \& Gwilym, O. (2000). Forecasting UK stock market volatility. Applied Financial Economics, 2000, 10, 435-448.

Nelson, D. B. (1991). Conditional Heteroskedasticity in Asset Returns: A New Approach. Econometrica, 59, 347-370.

Ng, H. G. \& McAleer, M. (2004). Recursive Modelling of Symmetric and Asymmetric Volatility in the Presence of Extreme Observations. International Journal of Forecasting, 20, 115-129.

Pasha, G. R., Tahira, Q. \& Aslam, M. (2007). Estimating and Forecasting Volatility of Financial Time Series in Pakistan with GARCH-type Models. The Lahore Journal of Economics, 12(2), 115-149.

Peiró, A. (2001). Skewness in Individual Stocks at Different Frequencies, WP-EC 2001-07: V-1486-2001 IVIE working papers.

Prymachenko, I. (2003). Stock Price Volatility and its Determinants on the Emerging Financial Market of Ukraine, Unpublished Thesis

Rehim, K. (2008). GARCH effects in another market: Modeling and forecasting Kraft prices and conditional volatility, Working Paper Series, The Center for Paper Business and Industry Studies, Georgia Institute of Technology, Atlanta, GA.

Rizwan, M. F. \& Khan, S. (2007). Stock Return Volatility in Emerging Equity Market (KSE): The Relative Effects of Country and Global Factors. International Review of Business Research Papers, 3(2), 362 - 375.

Schwert, G. W. (1990). Stock Volatility and Crash of 87. Review of Financial Studies, 3, 77-102.

Thomas, S. (1995). Heteroskedasticity Models on the Bombay Stock Exchange, Working Paper, University of Southern California, Department of Economics.

Turan, G., Bali, K. \& Demirtas, O. (2006). Testing Mean Reversion in Stock Market Volatility Unpublished Research Paper.

Zakoian, J. M. (1994). Threshold Heteroskedastic Models. Journal of Economic Dynamics and Control, 18, 931955.

Zhu, J. (2007). Pricing Volatility of Stock Returns with Volatile and Persistent Components. School of Economics and Management, Unpublished Research Paper. 